\title{
Alliance Ruptures and Resolutions in Personality Disorders
}

\author{
Nathalie Schenk ${ }^{1} \cdot$ Lukas Fürer $^{1} \cdot$ Ronan Zimmermann ${ }^{1,2} \cdot$ Martin Steppan $^{1} \cdot$ Klaus Schmeck $^{1}$ (D)
}

Accepted: 17 November 2020 / Published online: 11 December 2020

(C) The Author(s) 2020

\begin{abstract}
Purpose of Review This review provides an overview of the state of research on alliance ruptures and resolutions in the treatment of personality disorders (PDs). We discuss frequently used instruments to measure alliance ruptures and resolutions. We discuss the effectiveness of rupture resolution processes and highlight possible avenues for research to explore. Innovative assessments with the potential to reveal the link of ruptures and resolutions and mechanisms of psychotherapeutic change are discussed.

Recent Findings The assessment of alliance rupture and resolutions is heterogeneous. Instruments vary largely with respect to a direct or indirect assessment, the time resolution of assessment (integral therapy, phase, session, event), session sampling strategy and perspectives (patient, therapist, observer). The heterogeneity in the instruments and study designs impedes comparability and interpretation of the findings. Results support the hypothesis that ruptures are more frequent in PD. Results also point towards beneficial effects of rupture resolution patterns, early alliance quality, and resolution complexity. Few studies control findings for pretreatment factors.

Summary Evidence points to the direction that rupture resolution processes can be considered a general principle of change in the treatment of PD. The concept of alliance ruptures and resolutions provides a useful tool for the management of the therapeutic alliance and its moments of deteriorations throughout the treatment course. Dimensional pretreatment personality functioning is considered a key variable in future studies to highlight what works for whom.
\end{abstract}

Keywords Rupture resolution $\cdot$ Personality disorder $\cdot$ Alliance

\section{Introduction}

It is argued that relationship factors are not only a byproduct of the psychotherapeutic encounter but also a vehicle of change per se (Task Force Division 29: [1, 2]). Building upon a relational approach $[3 \bullet \bullet]$, alliance research concerned with personality disorders (PDs) investigates the assumption that the process of rupture resolution brings about change $[4,5]$. The NICE guidelines recommend the building and management of the therapeutic alliance as a general principle of change in the treatment of PD [6]. However, patients with PD have general difficulties in forming interpersonal relationships, including

Nathalie Schenk and Lukas Fürer contributed equally to this work.

This article is part of the Topical collection on Personality Disorders

Klaus Schmeck

klaus.schmeck@upk.ch

1 Child and Adolescent Psychiatric Research Department, Psychiatric University Hospitals of the University of Basel, Basel, Switzerland

2 Division of Clinical Psychology and Psychotherapy, Faculty of Psychology, University of Basel, Basel, Switzerland the therapeutic relationship, due to their impairments in self and interpersonal functioning [7].

Safran and Muran [8] conceptualize the therapeutic alliance as a dynamic and relational entity that is continuously built and negotiated by patient and therapist. In this negotiation process, alliance ruptures with minor or major significance emerge inevitably. Alliance ruptures are described as momentary deteriorations in the therapeutic alliance resulting from a lack of collaboration regarding the goals and tasks of the treatment or resulting from strains in the emotional bond [9•]. Withdrawal and confrontation ruptures can be differentiated by their movement dynamics (against therapist or therapy work versus avoiding therapist or therapy work). The rupture resolution is the process of recognizing, exploring, and repairing alliance ruptures with the aim to reestablish the collaboration and to explore the patient's underlying needs and intrapsychic conflicts. The resolution process that is initiated by the therapist has the potential to enable a corrective experience that is held to be therapeutic in itself [4]. Safran and Muran [5] suggest that alliance ruptures disclose a window into core interpersonal schemes. Insofar, the therapeutic relationship enables an interpersonal learning field in which 
representations of the self and others, interpersonal schemes, and the needs for agency versus communion can be probed and adapted [3••]. Resolution strategies can be immediate, focusing on the reestablishment of the collaboration, or expressive, exploring the patients' needs and intrapsychic conflicts underlying the alliance rupture [10].

Schenk et al. [11•] provide a detailed description of the occurrences of ruptures and resolutions in therapies with adolescents with borderline personality disorder (BPD). The most typical alliance ruptures were minimal response, denial, avoidant storytelling, patient defends self against therapist, complaints against therapist, and rejecting therapist intervention. Therapists typically used the resolution strategies to invite the patient to discuss thoughts and feelings about the therapist or some aspect of therapy, to validate the patient's defensive posture and to illustrate tasks or provide a rationale for treatment (Schenk et al. [11•]). The following transcript demonstrates a short rupture-resolution sequence of a therapy session with a 16-year-old adolescent with BPD:

T: How are you?

P: Not good.

T: Not good?

P: No. $($ Pause) $=>$ Minimal response rupture

T: what happened?

P: I do not know. (Pause) $=>$ Minimal response rupture

$\mathrm{T}$ : Is anything bothering you?

P: No. $=>$ Denial Rupture

T: How does it come you feel not good?

P: I do not know, it's like always. => Minimal response rupture

T: And what does it mean when you say that you are not doing well, any thoughts or feelings about that? => Resolution "therapist invites the patient to discuss thoughts or feelings"

P: I do not feel happy, just empty.

T: Mmmh. Do you already know that feeling from yourself?

P: I do not know. (Long pause) => Minimal response rupture

T: Hmm, I have the feeling we are stuck here right now. I have the feeling you could feel pressured by me asking you all these questions. Do you feel this way with me?

Resolution attempt "the therapist discloses his/her internal experience of the patient-therapist interaction".

\section{Instruments of Alliance Ruptures and Resolutions}

Alliance ruptures and resolutions can be measured with direct or indirect instruments, through different perspectives (patient, therapist observer), on different assessment levels (session, specific time windows, episodes, markers, speaking turns, utterances) and at different time points (successive therapy sessions, phases, specific sessions, between sessions, retrospective in interviews).

Table 1 presents frequently used direct and indirect instruments of alliance ruptures. The direct assessment is based on observer ratings or retrospective self-report questionnaires aiming directly at rupture resolution episodes. The indirect assessment means that the alliance is measured and inferences towards alliance ruptures and resolutions are drawn from sudden and significant fluctuations in the global alliance. Eubanks-Carter et al. [24] provide an overview of the quantitative naturalistic methods for detecting alliance ruptures on the basis of global alliance measures.

The direct instruments with observer ratings (e.g., 3RS, CIS) enable a detailed investigation of the process of the alliance negotiation based on the event paradigm [25]. This finegrained analysis is particularly of interest to understand underlying principles of change through rupture resolution processes. Using task analysis, the performance of rupture resolutions can be studied in detail as done by Aspland et al. [26], Bennett et al. [27•], and Daly et al. [28]. Furthermore, with descriptive studies the incidence and phenomenological quality of ruptures and resolutions can be examined in different patient samples $[11 \cdot, 29,30]$. Limitations are that the coding is time and cost intensive and therefore often restricted to small sample sizes which impedes generalizability and inferences to the treatment outcome. The indirect instruments derived from self-report ratings of the alliance assess changes in the quality of the alliance on a global level. They estimate the impact of possible but not directly measured ruptures and likely measure major but not minor ruptures. Indirect measures allow the investigation of large patient samples on a macro level of investigation. They are feasible for the study of withinpatient and between-patient effects of rupture resolution processes in relation to the treatment outcome. However, the indirect measures are less accurate and might be biased regarding construct validity. In comparison to observer ratings, selfreport measures underestimate the amount of alliance ruptures $[29,31]$.

\section{Influence of PD Traits on Rupture Resolution Processes}

Theoretical and clinical considerations about the interpersonal nature of different PDs allow assumptions towards the quality of ruptures encountered with these patients $[3 \bullet \bullet, 32 \bullet]$. For example, withdrawal ruptures may be more frequent in patients who are overly compliant, fearful, and averse to interpersonal conflicts such as cluster $\mathrm{C}$ patients. Confrontation ruptures may be more frequent in patients with cluster $\mathrm{A}$ or 
Table 1 Direct and indirect instruments of alliance ruptures

\begin{tabular}{|c|c|c|c|}
\hline & Instruments & Perspective & Details \\
\hline \multirow[t]{4}{*}{ Direct instruments } & $\begin{array}{l}\text { Rupture Resolution Rating } \\
\text { System (3RS; [12]) }\end{array}$ & Observer rating & $\begin{array}{l}\text { Contains } 7 \text { withdrawal and } 7 \text { confrontation rupture markers as well } \\
\text { as } 10 \text { resolution markers. Markers are rated on a significance } \\
\text { rating scale and an overall resolution rating scale. Units of } \\
\text { coding are speaking turns, } 1 \text { - or } 5 \text {-min windows or defining start } \\
\text { and stop markers for each episode. }\end{array}$ \\
\hline & $\begin{array}{l}\text { Collaborative Interaction Scale- } \\
\text { Revised (CIS-R; [13]) }\end{array}$ & Observer rating & $\begin{array}{l}\text { 29-item rating scale with two subscales CIS-P and CIS-T. CIS-P } \\
\text { defines direct and indirect rupture markers and direct and } \\
\text { indirect collaborative processes of the patient. CIS-T defines } \\
\text { direct and indirect collaborative interventions, rupture and } \\
\text { therapist interventions. Coding is done within narrative units. } \\
\text { Ruptures and resolutions can be coded for both the patient and } \\
\text { the therapist. }\end{array}$ \\
\hline & $\begin{array}{l}\text { Harper's }[14,15] \text { manual of } \\
\text { rupture markers }\end{array}$ & Observer rating & $\begin{array}{l}\text { Defines } 10 \text { markers of confrontation ruptures and } 8 \text { markers of } \\
\text { withdrawal ruptures. The analysis is performed on the level of } \\
\text { speaking turns. }\end{array}$ \\
\hline & $\begin{array}{l}\text { The Structural Analysis of Social } \\
\text { Behavior (SASB; [16]) }\end{array}$ & Observer rating & $\begin{array}{l}\text { Measures interpersonal behavior of the patient and therapist with } \\
\text { the octants "focus on other" and "focus on self" with two } \\
\text { orthogonal dimensions interdependence (from autonomy to } \\
\text { involvement) and affiliation (from hostility to friendliness). } \\
\text { Alliance ruptures were rated as patient behaviors of appeasing, } \\
\text { avoiding and blaming. Resolutions were rated as patient and } \\
\text { therapist expressing and therapist affirming and directing [9•]. }\end{array}$ \\
\hline $\begin{array}{l}\text { Direct and indirect } \\
\text { instruments }\end{array}$ & Post-Session- Questionnaire [17] & Patient, therapist & $\begin{array}{l}\text { Combines the session evaluation questionnaire (SEQ; [18]) and } \\
\text { direct questions of whether or not there was a problematic event } \\
\text { in the relationship during the session and when these events } \\
\text { occurred. Patients rate the tension of the problematic event on a } \\
\text { 5-point Likert scale. The SEQ assesses the session impact } \\
\text { (subscales depth and smoothness) and post-session feelings of } \\
\text { positivity and arousal. }\end{array}$ \\
\hline \multirow[t]{5}{*}{ Indirect instruments } & $\begin{array}{l}\text { Working Alliance Inventory } \\
\text { Short Form (WAI-SF; [19]) }\end{array}$ & $\begin{array}{l}\text { Patient, therapist, } \\
\text { observer }\end{array}$ & $\begin{array}{l}\text { 12-item self-report with three subscales goals, tasks and bond of } \\
\text { the therapeutic alliance. It is mostly administered at the end of } \\
\text { sessions. }\end{array}$ \\
\hline & $\begin{array}{l}\text { California Psychotherapy } \\
\text { Alliance Scales (CALPAS; } \\
[20])\end{array}$ & $\begin{array}{l}\text { Patient, therapist, } \\
\text { observer }\end{array}$ & $\begin{array}{l}\text { The subscales patient working capacity, patient commitment, } \\
\text { working strategy consensus and therapist understanding and } \\
\text { involvement are assessed. Observer rating is done on the } \\
\text { session level. }\end{array}$ \\
\hline & $\begin{array}{l}\text { Vanderbilt Therapeutic Alliance } \\
\text { Scale-Revised Short Form } \\
\text { (VTAS-R SF; [21]) }\end{array}$ & Observer & $\begin{array}{l}\text { 5-item rating scale with two subscales patient contribution and } \\
\text { patient-therapist interaction. The items reflect Bordin's } \\
\text { theoretical constructs bond, goals and tasks. Items are scored on } \\
\text { a 6-point Likert scale. The coding is done on session level. }\end{array}$ \\
\hline & $\begin{array}{l}\text { Alliance Negotiation Scale } \\
\text { (ANS; [22]) }\end{array}$ & Patient & $\begin{array}{l}\text { 12-item self-report scale that assesses the degree of constructive } \\
\text { negotiation of disagreements about tasks and goals from the } \\
\text { perspective of the patient. }\end{array}$ \\
\hline & $\begin{array}{l}\text { The Agnew Relationship } \\
\text { Measure (ARM; [23]) }\end{array}$ & Patient, therapist & $\begin{array}{l}\text { 26-item questionnaire measuring the quality of the therapeutic } \\
\text { relationship from the perspective of the therapist and the patient. }\end{array}$ \\
\hline
\end{tabular}

B PD as they use more direct and overt strategies to disclose strains in the alliance like criticize or pressure the therapist. Unfortunately, there is no empirical evidence emphasizing these hypotheses.

Zilcha-Mano [33・•] proposed to differentiate between traitlike (i.e., pretreatment tendencies of the patient to form relationships with others) and state-like components of alliance (i.e., changes in relationship functioning through the interaction with the therapist). It is hypothesized that patients with PD present with lower trait-like pretreatment interpersonal functioning that leads to problems in building and maintaining a stable working alliance. This could lead to more ruptures during the process and a lower (early) alliance quality compared to other clinical groups.

In the validation study of the 3RS, Eubanks et al. [12] found ruptures in almost every session of a psychotherapy with patients with varying diagnoses. However, Schenk et al. [11•] used the $3 \mathrm{RS}$ to analyze the complete treatment of a sample of ten adolescents with BPD. In $72 \%$ of the sessions, at least one rupture was observed. 
Colli et al. [13] compared 15 PD patients (cluster B and C) with 15 patients suffering from other psychiatric disorders. In PD patients, rupture markers were observed more frequently than in non-PD patients (tasks and goals marker: $F=4.7$, $p=.031$, discouragement marker: $F=4.0, p=.046)$. Interestingly, they also found that therapists of PD patients tended to be more hostile and less clear and used more perseverations than non-PD therapists. However, the PD therapists also provided more supportive, explicative, and expressive interventions targeting alliance ruptures than the non-PD therapists.

Tufekcioglu et al. [34] tested whether cluster C PD or personality traits impact the early alliance compared to non-PD patients. They found that PD patients rated a higher rupture intensity than non-PD patients $(F=16.6, r=.43, p<.01)$. Furthermore, they found that the pretreatment personality traits of high impulsivity, dysregulation, and lability (but not diagnoses) were associated with higher patient-reported rupture intensity. Coutinho et al. [29] found that patients with PD experience a lower alliance quality (measured with the WAI) and more frequent withdrawal and confrontation ruptures (3RS) compared to patients with depression and anxiety disorders.

In conclusion, there is evidence that confrontation and withdrawal ruptures are more frequent in PD than other clinical samples. Differences between PD and non-PD patients seem to also surface when observing therapist behavior. The findings can be interpreted in the light of a trait-like alliance component of lower interpersonal functioning in PD patients, meaning that the quality of the therapeutic relationship is endangered from the beginning on by the severe interpersonal problems that are at the core of PD symptomatology.

\section{The Effects of Ruptures and Resolutions}

Studies concerned with the correlation between alliance and outcome focus on different characteristics of the alliance, depending on the instruments used. We review the outcomes of meta-analyses, literature investigating early alliance, rupture resolution processes (e.g., significant fluctuations in WAI) and literature focusing on resolutions and their complexity. When trying to unveil the state-like components of alliance leading to change (curative interactions with therapists), one has to control for trait-like components (e.g., pretreatment personality functioning), setting the preconditions for a beneficial interpersonal relationship. Not all studies reviewed here do that.

Up to date there are two meta-analyses that report moderate effects of rupture resolution processes on the treatment outcome [9•, 35]. Safran et al. [35] summarized studies using indirect instruments of alliance ruptures. In this meta-analysis, the number of rupture resolution episodes was positively related to treatment outcome $(r=.24,95 \% C I[.09, .39]$, $p=.002, k=3, n=148)$. The meta-analysis of Eubanks et al. [9•] confirmed that rupture resolution processes are positively associated with the treatment outcome when using direct as well indirect measures $(r=.29, C I[.10, .47], d=.62$, $p=.003, k=11, n=1314)$. The effect was independent of type of treatment or type of instruments used. However, the timing of the assessment impacted the rupture resolution outcome relationship. An assessment in early sessions resulted in a lower association $(r=.13, z=1.90, p=.06)$, whereas an assessment across the complete course resulted in a stronger rupture resolution outcome association $(r=.38, z=3.13$, $p=.002)$. This is an encouraging result when hypothesizing that late sessions may better reflect state-like alliance components, whereas early sessions could be more influenced by the trait-like pretreatment conditions.

Considering early alliance, Strauss et al. [36] found that patients (obsessive-compulsive PD and avoidant PD) who showed higher pretreatment personality pathology presented with a lower early alliance $(r=-.40, p<.05)$, and in turn, better early alliance predicted a higher number of sessions attended $(r=.38, p<.05)$. Also, better early alliance predicted gains in all post-treatment outcome measures (personality pathology: $r=-.40, p<.05$, depression score: $r=-.49$, $p<.01)$. Also, Muran et al. [37] found that lower early rupture intensity was associated with higher post-treatment interpersonal functioning (cluster $\mathrm{C}$ and NOS, patient rated: $r=-.35$, $p<.01$; therapist rated: $r=-.32, p<.01)$. In a youth BPD sample, Gersh et al. [38] found that more early ruptures were associated with poorer outcomes in social functioning $(r=.32$, $p<.05)$.

There is evidence for rupture resolution patterns (significant fluctuations or dips in alliance implying ruptures, returning to baseline and above, implying resolution). Schenk et al. [11•] assessed ruptures with the $3 R S$ on a session-by-session basis. Nonlinear rupture trajectories were found on the individual level with high intra- and interindividual differences. In adolescent patients with BPD, ruptures tended to emerge in phases. Also Stevens et al. [39] found that $50 \%$ of patients (cluster C and NOS) showed local rupture resolution patterns. There was however no association to be found between the occurrence of rupture resolution patterns and outcome. On the other hand, Strauss et al. [36] found that $56 \%$ of their sample showed rupture resolution patterns. Higher pretreatment personality pathology (cluster $\mathrm{C}$ ) resulted in less rupture resolution patterns $(r=.43, p<.05)$. Occurrence of rupture resolution patterns in turn predicted improvement in personality pathology $(r=-.53, p<.01)$ and depression $(r=.41, p<.05)$.

When looking at resolutions, Muran et al. [37] found that patients (cluster $\mathrm{C}$ and NOS) who experience more resolutions of ruptures were less likely to drop out $(r=-.29, p<.05)$. In contrast, for adolescents with BPD, Schenk et al. $[11 \bullet, 40]$ 
showed that although dropouts experienced a higher frequency of alliance ruptures per session in comparison to the completers, therapists of the dropout patients applied an equal proportion of resolutions to ruptures as the therapists of the completers. This indicates that the mere number of resolutions was not protective of dropping out in this particular sample. In the same vein, Gersh et al. [38] found that a higher number of resolutions in late sessions were associated with improvement in BPD symptoms $(r=-.67, p<.05)$. Daly et al. [28] demonstrated that the complexity of resolution strategies was associated with the treatment outcome in a sample of three recovered and three unrecovered adolescent patients with BPD. Complexity was conceptualized by the number of stages of Bennet's [27•] resolution stage model employed by therapists. The resolution stage model was defined in a task analytical effort and engulfs nine hierarchical (sequential) stages, namely acknowledgment, exploration, linking and explanation, negotiation, consensus, understanding and assimilating warded off feelings, further explanation, change to patterns/aim, and closure. Daly et al. [28] showed that resolved rupture episodes are characterized by more and higher (negotiation to closure) model stages. Further, therapists of recovered patients used more and higher stage resolutions than therapists of unrecovered patients who more often remained at a lower stage of resolution. In contrast, Boritz et al. [30] found that withdrawal ruptures tended to persist over time in the unrecovered but not the recovered patients (BPD) despite the degree to which they were resolved in the prior session.

In summary, there is first meta-analytical evidence for the beneficial effect of rupture resolution processes during psychotherapy. When looking at PD literature, early alliance seems to influence dropout status and positively predict outcome. However, Strauss et al. [36] found that early alliance is associated with pretreatment pathology, indicating that the beneficial effects of early alliance are found in patients that are able to build a stable therapeutic relationship in the early phase of therapy. In the same vein, the underlying principles of change in rupture resolution patterns still remain unclear given their possible link to pretreatment personality pathology. The studies concerned with resolutions and their complexity during the process point towards favorable effects of higher order resolutions and resolutions in the later phase of therapy. However, they also indicate that in some cases the amount and the complexity of resolutions remain futile. The contextual factors (therapist effects, patient interpersonal dysfunction) hindering the therapeutic effect of offered resolutions remain an important avenue for future research.

\section{Rupture Resolution Training}

Eubanks-Carter et al. [41] have developed an alliance-focused training (AFT). Safran and Muran's publication on
Negotiating the Therapeutic Alliance: A Relational Treatment Guide [8] serves as a training manual. Muran et al. [42] have tested the additive effect of AFT during a 30-session CBT protocol for cluster C PD on interpersonal behavior (SASB). Therapists were introduced to AFT at different time intervals (after session 8 or 16) controlling for patient, therapist, and patient-therapist interactional effects. For patients, the introduction of AFT predicted a decrease in following behavior, an increase in expressiveness and a trend was found towards less avoidance and appeasement. For therapists, the onset of AFT training predicted a decrease in therapist blaming and directing and an increase in therapist affirmation and expressiveness. Findings demonstrate that the expressing behavior of the patient was positively related to treatment outcome and patient appeasing and blaming were negatively related to treatment outcome. The authors insofar were able to show that AFT resulted in beneficial changes of interpersonal processes in a CBT setting.

Although the study of Muran et al. [42] demonstrates meaningful changes in interpersonal behavior, the impact of rupture resolution training on the outcome level remains sparse. The meta-analyses of Eubanks et al. [9॰] did not support a significant effect of a rupture resolution training on the treatment outcome.

\section{Need for New Methods in Future Research}

The finding that a better alliance is associated with a better treatment outcome has been confirmed in numerous studies [43-45]. However, in these study designs, the alliance is treated as a fixed effect factor that is measured most often at the beginning of the therapy. Therefore, the dynamic quality of the alliance is neglected. With advanced statistical methods and study designs, the state- and traitlike components in the alliance-outcome association can be distinguished. This allows to analyze to what extent the alliance acts as a precondition to the therapeutic process (trait-like general relationship tendencies of the patient) or as a dynamic entity of the therapeutic relationship (i.e., state-like like rupture resolution processes) that operates as a vehicle of change [33・•]. However, the video analysis of critical events is very labor- and cost-intensive. This results in studies with either low or no repeated measurement or in studies with small sample sizes. Future research should therefore invest in automated methods to describe alliance characteristics using physiological [46, 47], vocal [48, 49], facial [50], and movement [51] information streams. Interpersonal processes have been proposed to mirror the quality of interactions; especially synchrony has been proposed as an integrative framework for the therapeutic alliance [52•]. This theoretical framework allows to focus on objectively measurable interpersonal 
behavior and to complement the subjective experience and linguistic interaction studied so far in alliance research [53]. Alternatively, machine-learning could be used to approximate critical events in psychotherapy based on automated information streams and to mark them for further manual evaluation. For example, minimal response withdrawal ruptures could be approximated by automated silence detection [40] and speaker diarization [54]. The extent of nonverbal movement synchrony has been associated with patient-rated relationship quality [51], dropout status, and improvement [55]. Reich et al. [49] found that vocal synchrony in turn was negatively associated with the patient-rated working alliance. The here proposed methods assess alliance ruptures only indirectly but on a fine-grained temporal level in large samples sizes over the whole psychotherapeutic process. This would allow to study bridging concepts like synchrony or emotion regulation in relation to working alliance processes for PD specifically.

\section{Conclusion}

Alliance ruptures and their resolution in PD are studied through direct (observer-based methods: 3RS, CIS) and indirect methods (e.g., questionnaires: PSQ, WAI). Horvath [56] estimates over 70 different instruments that operationalize the alliance based on different theoretical constructs. The biggest problems of the field are objectivity and comparability. Studies are sparse and highly heterogeneous (PD cluster, research aims, session sampling, methods), impeding the comparability and interpretation of findings. Concordance of direct and indirect measures of alliance ruptures must be considered low [31, 57]. In order to avoid a forest of unconnected and therefore hard to summarize findings, methodological objectivity should be considered a key interest for the field.

Throughout the literature there is frequent use of cluster $\mathrm{C}$ patient samples; cluster A and B studies are highly encouraged. It is hypothesized that PD diagnoses influence the quality of ruptures encountered through their characteristic interpersonal constraints $[3 \bullet \bullet, 32 \bullet]$. It is therefore important to acquire and compare findings for all different types of PD. Moving towards the dimensional ICD-11 diagnosis, future studies should include dimensional personality functioning as covariate variables to embed findings. Results by Strauss et al. [36] or Muran et al. [37] already point towards the direction that personality functioning is a more feasible moderator and outcome variable than the number of SCID items. Further, few studies test for trait-like pretreatment factors moderating the alliance outcome association. Dimensional pretreatment personality functioning (DSM-5; $[58 \bullet$ 59•]) is considered an important variable for future studies, in order to report what has worked for whom.
Funding Open access funding provided by University of Basel.

Open Access This article is licensed under a Creative Commons Attribution 4.0 International License, which permits use, sharing, adaptation, distribution and reproduction in any medium or format, as long as you give appropriate credit to the original author(s) and the source, provide a link to the Creative Commons licence, and indicate if changes were made. The images or other third party material in this article are included in the article's Creative Commons licence, unless indicated otherwise in a credit line to the material. If material is not included in the article's Creative Commons licence and your intended use is not permitted by statutory regulation or exceeds the permitted use, you will need to obtain permission directly from the copyright holder. To view a copy of this licence, visit http://creativecommons.org/licenses/by/4.0/.

\section{References}

Papers of particular interest, published recently, have been highlighted as:

- Of importance

-• Of major importance

1. Ackerman SJ, Benjamin LS, Beutler LE, Gelso CJ, Goldfried MR, Hill C, et al. Empirically supported therapy relationships: conclusions and recommendations fo the Division 29 Task Force. Psychother Theory Res Pract Train. 2001;38(4):495-7. https://doi. org/10.1037/0033-3204.38.4.495.

2. Norcross JC. Psychotherapy relationships that work: therapist contributions and responsiveness to patients. New York: Oxford University Press; 2002.

3.• Tufekcioglu S, Muran JC. A relational approach to personality disorder \& alliance rupture. In: Integrated treatment for personality disorders. New York: Guilford; 2014. Presenting a theoretical link between $P D$ and alliance.

4. Safran JD. Breaches in the therapeutic alliance - an arena for negotiating authentic relatedness. Psychotherapy. 1993;30(1):11-24. https://doi.org/10.1037/0033-3204.30.1.11.

5. Safran JD, Muran JC. The resolution of ruptures in the therapeutic alliance. J Consult Clin Psychol. 1996;64(3):447-58. https://doi. org/10.1037//0022-006x.64.3.447.

6. National Institute for Health and Care Excellence. Borderline personality disorder: recognition and management (NICE guideline 78). London: Department of Health; 2009. https://www.nice.org. uk/guidance/cg78.

7. American Psychiatric Association, DSM-5 Task Force. Diagnostic and statistical manual of mental disorders: DSM-5 ${ }^{\mathrm{TM}}$, 5th ed. American Psychiatric Publishing, Inc.; 2013. https://doi.org/10. 1176/appi.books.9780890425596.

8. Safran JD, Muran JC. Negotiating the therapeutic alliance: a relational treatment guide. New York: Guilford Press; 2000.

9. Eubanks CF, Muran JC, Safran JD. Alliance rupture repair: a metaanalysis. Psychotherapy (Chic). 2018;55(4):508-19. https://doi. org/10.1037/pst0000185. Meta-analyses on the effects of rupture-resolution and resolution trainings on patient outcomes.

10. Muran JC. Confessions of a New York rupture researcher: an insider's guide and critique. Psychother Res. 2019;29(1):1-14. https://doi.org/10.1080/10503307.2017.1413261.

11. Schenk N, Zimmermann R, Fürer L, Krause M, Weise S, Kaess M, et al. Trajectories of alliance ruptures in the psychotherapy of adolescents with borderline personality pathology: timing, typology 
and significance. Res Psychother 2019;22(2):348. https://doi.org/ 10.4081/ripppo.2019.348. Presents graphics of alliance trajectories in adolescents with a borderline personality pathology. Provides a session-to-session measurement of complete psychotherapies with the 3RS.

12. Eubanks CF, Lubitz J, Muran JC, Safran JD. Rupture resolution rating system (3RS): development and validation. Psychother Res. 2019;29(3):306-19. https://doi.org/10.1080/10503307.2018. 1552034.

13. Colli A, Gentile D, Condino V, Lingiardi V. Assessing alliance ruptures and resolutions: reliability and validity of the collaborative interactions scale-revised version. Psychother Res. 2019;29(3): 279-92. https://doi.org/10.1080/10503307.2017.1414331.

14. Harper H. Coding guide I: identification of confrontation challenges in exploratory therapy. Sheffield: University of Sheffield; 1989.

15. Harper H. Coding guide II: identification of withdrawal challenges in exploratory therapy. Sheffield: University of Sheffield; 1989.

16. Benjamin LS. SASB - a bridge between personality theory and clinical-psychology. Psychol Inq. 1994;5(4):273-316. https://doi. org/10.1207/s15327965pli0504_1.

17. Samstag LW, Batchelder ST, Muran JC, Safran JD, Winston A. Early identification of treatment failures in short-term psychotherapy. An assessment of therapeutic alliance and interpersonal behavior. J Psychother Pract Res. 1998;7(2):126-43.

18. Stiles WB. Measurement of the impact of psychotherapy sessions. J Consult Clin Psychol. 1980;48(2):176-85. https://doi.org/10.1037/ 0022-006x.48.2.176.

19. Horvath AO, Greenberg LS. Development and validation of the working alliance inventory. J Couns Psychol. 1989;36(2):223-33. https://doi.org/10.1037/0022-0167.36.2.223.

20. Marmar CR, Gaston L. California Psychotherapy Alliance Scales (CALPAS) manual. San Francisco: University of California; 1988. Unpublished manuscript.

21. Shelef K, Diamond GM. Short form of the revised Vanderbilt therapeutic alliance scale: development, reliability, and validity. Psychother Res. 2008;18(4):433-43. https://doi.org/10.1080/ 10503300701810801 .

22. Doran JM, Safran JD, Waizmann V, Bolger K, Muran JC. The alliance negotiation scale: psychometric construction and preliminary reliability and validity analysis. Psychother Res. 2012;22(6): 710-9. https://doi.org/10.1080/10503307.2012.709326.

23. Agnew-Davies R, Stiles WB, Hardy GE, Barkham M, Shapiro DA. Alliance structure assessed by the Agnew Relationship Measure (ARM). Br J Clin Psychol. 1998;37(2):155-72. https://doi.org/10. 1111/j.2044-8260.1998.tb01291.x.

24. Eubanks-Carter C, Gorman BS, Muran JC. Quantitative naturalistic methods for detecting change points in psychotherapy research: an illustration with alliance ruptures. Psychother Res. 2012;22(6):62137. https://doi.org/10.1080/10503307.2012.693772.

25. Greenberg LS. Change process research. J Consult Clin Psychol. 1986;54(1):4-9. https://doi.org/10.1037//0022-006x.54.1.4.

26. Aspland H, Llewelyn S, Hardy GE, Barkham M, Stiles W. Alliance ruptures and rupture resolution in cognitive-behavior therapy: a preliminary task analysis. Psychother Res. 2008;18(6):699-710. https://doi.org/10.1080/10503300802291463.

27. Bennett D, Parry G, Ryle A. Resolving threats to the therapeutic alliance in cognitive analytic therapy of borderline personality disorder: a task analysis. Psychol Psychother. 2006;79(Pt 3):395-418. https://doi.org/10.1348/147608305X58355 Task analytical model of resolution in cognitive analytic therapy providing in-depth description of resolution efforts.

28. Daly AM, Llewelyn S, McDougall E, Chanen AM. Rupture resolution in cognitive analytic therapy for adolescents with borderline personality disorder. Psychol Psychother. 2010;83(Pt 3):273-88. https://doi.org/10.1348/147608309X481036.
29. Coutinho J, Ribeiro E, Fernandes C, Sousa I, Safran JD. The development of the therapeutic alliance and the emergence of alliance ruptures. [El desarrollo de la alianza terapéutica y la aparición de rupturas en la alianza]. An de Psicol. 2014;30(3). https://doi.org/10. 6018/analesps.30.3.168911.

30. Boritz T, Barnhart R, Eubanks CF, McMain S. Alliance rupture and resolution in dialectical behavior therapy for borderline personality disorder. J Personal Disord. 2018;32(Suppl):115-28. https://doi. org/10.1521/pedi.2018.32.supp.115.

31. Sommerfeld E, Orbach I, Zim S, Mikulincer M. An in-session exploration of ruptures in working alliance and their associations with clients' core conflictual relationship themes, alliance-related discourse, and clients' postsession evaluations. Psychother Res. 2008;18(4):377-88. https://doi.org/10.1080/10503300701675873.

32. Bender DS. The therapeutic alliance in the treatment of personality disorders. J Psychiatr Pract. 2005;11(2):73-87. https://doi.org/10. 1097/00131746-200503000-00002 Clinical considerations and theory about the link between the interpersonal nature of personality disorders and rupture resolution.

33.• Zilcha-Mano S. Is the alliance really therapeutic? Revisiting this question in light of recent methodological advances. Am Psychol. 2017;72(4):311-25. https://doi.org/10.1037/a0040435 Introduces the differentiation between trait-like and state-like components in alliance and bringing to important new avenues for alliance research.

34. Tufekcioglu S, Muran JC, Safran JD, Winston A. Personality disorder and early therapeutic alliance in two time-limited therapies. Psychother Res. 2013;23(6):646-57. https://doi.org/10.1080/ 10503307.2013.843803.

35. Safran JD, Muran JC, Eubanks-Carter C. Repairing alliance ruptures. Psychotherapy (Chic). 2011;48(1):80-7. https://doi.org/10. 1037/a0022140

36. Strauss JL, Hayes AM, Johnson SL, Newman CF, Brown GK, Barber JP, et al. Early alliance, alliance ruptures, and symptom change in a nonrandomized trial of cognitive therapy for avoidant and obsessive-compulsive personality disorders. J Consult Clin Psychol. 2006;74(2):337-45. https://doi.org/10.1037/0022-006X. 74.2.337.

37. Muran JC, Safran JD, Gorman BS, Samstag LW, Eubanks-Carter $\mathrm{C}$, Winston A. The relationship of early alliance ruptures and their resolution to process and outcome in three time-limited psychotherapies for personality disorders. Psychotherapy (Chic). 2009;46(2): 233-48. https://doi.org/10.1037/a0016085.

38. Gersh E, Hulbert CA, McKechnie B, Ramadan R, Worotniuk T, Chanen AM. Alliance rupture and repair processes and therapeutic change in youth with borderline personality disorder. Psychol Psychother. 2017;90(1):84-104. https://doi.org/10.1111/papt. 12097

39. Stevens CL, Muran JC, Safran JD, Gorman BS, Winston A. Levels and patterns of the therapeutic alliance in brief psychotherapy. Am J Psychother. 2007;61(2):109-29. https://doi.org/10.1176/appi. psychotherapy.2007.61.2.109.

40. Zimmermann R, Furer L, Schenk N, Koenig J, Roth V, SchluterMuller S, et al. Silence in the psychotherapy of adolescents with borderline personality pathology. Pers Disord. 2020. https://doi.org/ 10.1037/per0000402

41. Eubanks-Carter C, Muran JC, Safran JD. Alliance-focused training. Psychotherapy (Chic). 2015;52(2):169-73. https://doi.org/10.1037/ a0037596.

42. Muran JC, Safran JD, Eubanks CF, Gorman BS. The effect of alliance-focused training on a cognitive-behavioral therapy for personality disorders. J Consult Clin Psychol. 2018;86(4):384-97. https://doi.org/10.1037/ccp0000284.

43. Fluckiger C, Del Re AC, Wampold BE, Horvath AO. The alliance in adult psychotherapy: a meta-analytic synthesis. Psychotherapy (Chic). 2018;55(4):316-40. https://doi.org/10.1037/pst0000172. 
44. Horvath AO, Del Re AC, Fluckiger C, Symonds D. Alliance in individual psychotherapy. Psychotherapy (Chic). 2011;48(1):916. https://doi.org/10.1037/a0022186.

45. Martin DJ, Garske JP, Davis MK. Relation of the therapeutic alliance with outcome and other variables: a meta-analytic review. J Consult Clin Psychol. 2000;68(3):438-50.

46. Kleinbub JR. State of the art of interpersonal physiology in psychotherapy: a systematic review. Front Psychol. 2017;8:2053. https:// doi.org/10.3389/fpsyg.2017.02053.

47. Marci CD, Orr SP. The effect of emotional distance on psychophysiologic concordance and perceived empathy between patient and interviewer. Appl Psychophysiol Biofeedback. 2006;31(2):11528. https://doi.org/10.1007/s10484-006-9008-4.

48. Imel ZE, Barco JS, Brown HJ, Baucom BR, Baer JS, Kircher JC, et al. The association of therapist empathy and synchrony in vocally encoded arousal. J Couns Psychol. 2014;61(1):146-53. https://doi. org/10.1037/a0034943.

49. Reich CM, Berman JS, Dale R, Levitt HM. Vocal synchrony in psychotherapy. J Soc Clin Psychol. 2014;33(5):481-94. https:// doi.org/10.1521/jscp.2014.33.5.481.

50. Steppan M, Zimmermann R, Fürer L, Schenk N, Schmeck K. Machine learning facial emotion recognition in psychotherapy research. A useful approach? PsyArXiv. 2020. https://doi.org/10. 31234/osf.io/wpa5e.

51. Ramseyer F, Tschacher W. Nonverbal synchrony in psychotherapy: coordinated body movement reflects relationship quality and outcome. J Consult Clin Psychol. 2011;79(3):284-95. https://doi.org/ 10.1037/a0023419.

52. Koole SL, Tschacher W. Synchrony in psychotherapy: a review and an integrative framework for the therapeutic alliance. Front Psychol. 2016;7:862. https://doi.org/10.3389/fpsyg.2016.00862 Reviews the course of alliance research and introducing synchrony as a framework for alliance.
53. Tschacher W, Haken H, Kyselo M. Alliance: a common factor of psychotherapy modeled by structural theory. Front Psychol. 2015;6:421. https://doi.org/10.3389/fpsyg.2015.00421.

54. Fürer L, Schenk N, Roth V, Steppan M, Schmeck K, Zimmermann R. Supervised speaker diarization using random forests: a tool for psychotherapy process research. Front Psychol. 2020;11:1726. https://doi.org/10.3389/fpsyg.2020.01726.

55. Paulick J, Deisenhofer AK, Ramseyer F, Tschacher W, Boyle K, Rubel J, et al. Nonverbal synchrony: a new approach to better understand psychotherapeutic processes and drop-out. J Psychother Integr. 2018;28(3):367-84. https://doi.org/10.1037/ int0000099.

56. Horvath AO. Research on the alliance: knowledge in search of a theory. Psychother Res. 2018;28(4):499-516. https://doi.org/10. 1080/10503307.2017.1373204.

57. Coutinho J, Ribeiro E, Sousa I, Safran JD. Comparing two methods of identifying alliance rupture events. Psychotherapy (Chic). 2014;51(3):434-42. https://doi.org/10.1037/a0032171.

58. Goth K, Birkholzer M, Schmeck K. Assessment of personality functioning in adolescents with the LoPF-Q 12-18 Self-Report Questionnaire. J Pers Assess. 2018;100(6):680-90. https://doi.org/ 10.1080/00223891.2018.1489258 Describes the LoPF Questionnaire for the assessment of personality functioning in adolescents.

59. Hutsebaut J, Kamphuis JH, Feenstra DJ, Weekers LC, De Saeger $\mathrm{H}$. Assessing DSM-5-oriented level of personality functioning: development and psychometric evaluation of the Semi-Structured Interview for Personality Functioning DSM-5 (STiP-5.1). Pers Disord. 2017;8(1):94-101. https://doi.org/10.1037/per0000197 Describes the semi-structured interview for the assessment of personality functioning in adults.

Publisher's Note Springer Nature remains neutral with regard to jurisdictional claims in published maps and institutional affiliations. 